\title{
Recent spatial development of Svalbard strandflat vegetation over a period of 31 years
}

\author{
Myrtille Moreau, ${ }^{1}$ Dominique Laffly ${ }^{2} \&$ Thierry Brossard ${ }^{3}$ \\ 1 Laboratoire de Géographie Physique et Environnementale, 4 rue Ledru, FR-63057 Clermont-Ferrand, France \\ 2 Laboratoire Société, Environnement, Territoire, Domaine Universitaire, FR-64000 Pau, France \\ 3 Laboratoire Théoriser et Modéliser pour Aménager, 32 rue Mégevand, FR-25030 Besançon, France
}

Keywords

Correspondance analysis; plant dynamics; releves; Spitsbergen.

\section{Correspondence}

Myrtille Moreau, Laboratoire de Géographie Physique et Environnementale, 4 rue Ledru, FR-63057 Clermont-Ferrand, France. E-mail: myrtille.moreau@free.fr

doi:10.1111/j.1751-8369.2009.00119.x

\begin{abstract}
Vegetation succession was analysed at the forefields of two glaciers in Svalbard over an interval of 31 years (1975-2006). In 1975, 85 sampling sites were positioned along transects extending from the coastline to the glacier fronts: botanical observations were made at each sampling site. This protocol allowed us to carry out new observations in 2006 under the same conditions. Thus, it was possible to undertake a botanical assessment of species and taxa, and to see how the vegetation has changed with reference to a typology established by coupling correspondence analysis and ascending hierarchical classification. Vegetation succession at the sampling sites was also measured by using vectors positioned in the multidimensional space of correspondence analysis. In this way, the changes over the interval between seven vegetation types were plotted and mapped, and the colonization process was calibrated and dated against a series of reference stages, mainly since the end of the Little Ice Age.
\end{abstract}

Since the end of the Little Ice Age in Svalbard, dated there to around 1880 by Lefauconnier (1990), glaciers have receded, thereby opening up new areas for plant colonization. By referring to aerial photographs that show different stages of ice retreat, the different phases of plant colonization of moraines can be dated. Kuc (1964) observed the vegetation dynamics on the Treskelen glacier foreland at Hornsund in the southern part of the island of Spitsbergen. The foreland of the glacier Midre Lovénbreen, on the Brøggerhalvøya peninsula in northwest Spitsbergen, has been the subject of several studies. Brossard (1985) described the species colonization of some of its terminal moraines. Hodkinson et al. (2003) observed plant colonization along a single transect across the foreland (which did not cover the entire area). Moreau et al. (2005) and Moreau (2005) conducted a vegetation survey of 300 plots to study the influence of microtopography on vegetation cover. Elsewhere on Brøggerhalvøya, the foreland of the glacier Austre Brøggerbreen has been the subject of several studies. Nakatsubo et al. (1998) observed the respiration of the below-ground parts of vascular plants. Kume et al. (2003) assessed the growth forms of Saxifraga oppositifolia in different successional stages. Minami et al. (1997) sampled three transects to analyse the relationship between plant species and microtopographic forms. At Isfjord, in the central part of Spitsbergen, Ziaja \& Dubiel (1996) studied the colonization of the moraines of several mountain glaciers by vascular species.

The direct monitoring of vegetation succession on topographic features is less common. Klanderud \& Birks (2003) compared vegetation sampling sites in the Jotunheimen Mountains, Norway, in 1930-31 and 1998. Our approach is similar, and is based on field sessions in 1975 and 2006. The study area is a complex strandflat, featuring moraine belts and outwash plains ahead of two glaciers, as well as raised marine landforms. In 1975 , Brossard (1977) positioned 85 sampling sites along transects crossing the main landscape units. Wooden posts were used to mark these sampling sites. The plots were photographed and their plant species were systematically counted. Many of these markers survived, making it possible to identify most of the sampling sites in 2006, and to carry out a fresh survey based on the same protocol. The sampling sites were accurately positioned using a differential GPS set. Accordingly, we have two homogeneous series of vegetation sample data separated by a time interval of 31 years. To our knowledge, such data are unique in Svalbard. The aims of the study are: (1) to examine the differences between the two series of 
vegetation sample data; (2) to define the vegetation dynamics, in accordance with the different environmental contexts; and (3) to provide a spatial assessment of the vegetation succession.

\section{Study area}

The study was conducted $6 \mathrm{~km}$ east of Ny-Ålesund, in the vicinity of the J. Corbel French research base. This area is located between the Kongsfjorden fjord and the two fronts of the Midre Lovénbreen and Austre Lovénbreen glaciers. These glaciers reached their maximum advance more than a century ago, at the height of the Little Ice Age (Hagen et al. 1993). At that time, the ice tongues extended well over the piedmont. In the course of their retreat, which is still continuing, the glaciers have left several moraine belts that are major features of the present-day landscape (Lefauconnier 1990). Ahead of the moraines, a double limestone outcrop creates anchoring lines for several raised glaciomarine terraces (Forman 1990; Fig. 1), which are related to the post-Weichselian isostatic uplift. Mature tundra of the Northern Arctic Tundra Type defined by Elvebakk (1997) covers these glaciomarine terraces. The oldest terrace dates to around 9000 B.P. (Corbel 1966). Streams of water from the upper glacial basins have built an outwash plain of detrital cones (sandurs). As the ice retreated, the water flow became concentrated in just a few very dynamic and shifting water courses, whereas the secondary channels and cones were abandoned and then colonized by vegetation (Mercier 1998).

\section{Materials and method}

The observation protocol began in 1975, and was based on field sampling along transects extending from the coast to the glacier fronts (Fig. 1). The transects crossed all of the different landscape units in the area: marine terraces, active and inactive cones, and moraines. A total of 85 sampling sites were set up at intervals of roughly $200 \mathrm{~m}$. A 4- $\mathrm{m}^{2}$ area was delimited at each sampling site, providing a frame of reference for the observation sessions in 1975 and 2006. Other studies have shown that, as a rule, a $4-\mathrm{m}^{2}$ plot is large enough to cover the minimum area occupied by plant communities, except for extreme pioneering contexts, for which the minimum area is greater (Moreau 2005).

A portable $1-\mathrm{m}^{2}$ quadrat, subdivided into a $10 \times 10 \mathrm{~cm}$ grid, was used to observe the plant species, and each sampling site was photographed. It was possible, then, to locate the exact position of each sampling site with the minimum of error. During the 2006 session, 76 of the initial 85 sampling sites were identified. The missing plots had been located on active sandurs, and had therefore been washed away during the intervening period. For the observation protocol itself, our main concern was to avoid any artefact that might distort the information collected on the two dates. Species abundance was therefore omitted from the analysis, even though it was recorded in both surveys. Only presence/absence was considered, because species abundance estimates are somewhat subjective, and are unlikely to be stable over a 31-year

Fig. 1 Study area with transect positions and stages of the Midre Lovénbreen glacier retreat since the end of the Little Ice Age. The image background is a mosaic of two aerial photographs (provided by the the Norwegian Polar Institute) from 1966 and 1990. The photographs were digitized at 2-m resolution. The main part of the area was covered by an infrared photograph from 1990 (Norwegian Polar Institute reference number $S 905788)$. We have used a section dating from 1966 (Norwegian Polar Institute reference number 66 4455) to complete the coverage of the area. The two images were simply assembled after geometric correction, as they are used here merely to illustrate the sampling sites in their geographical context.

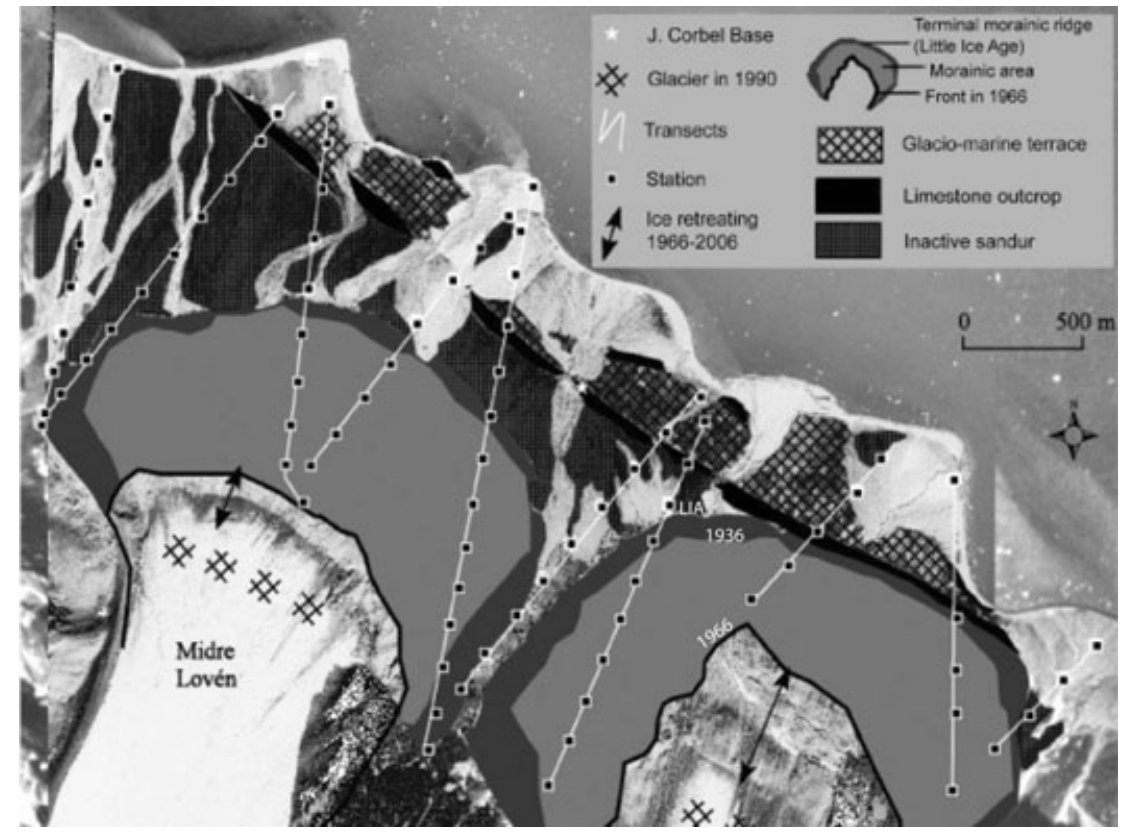




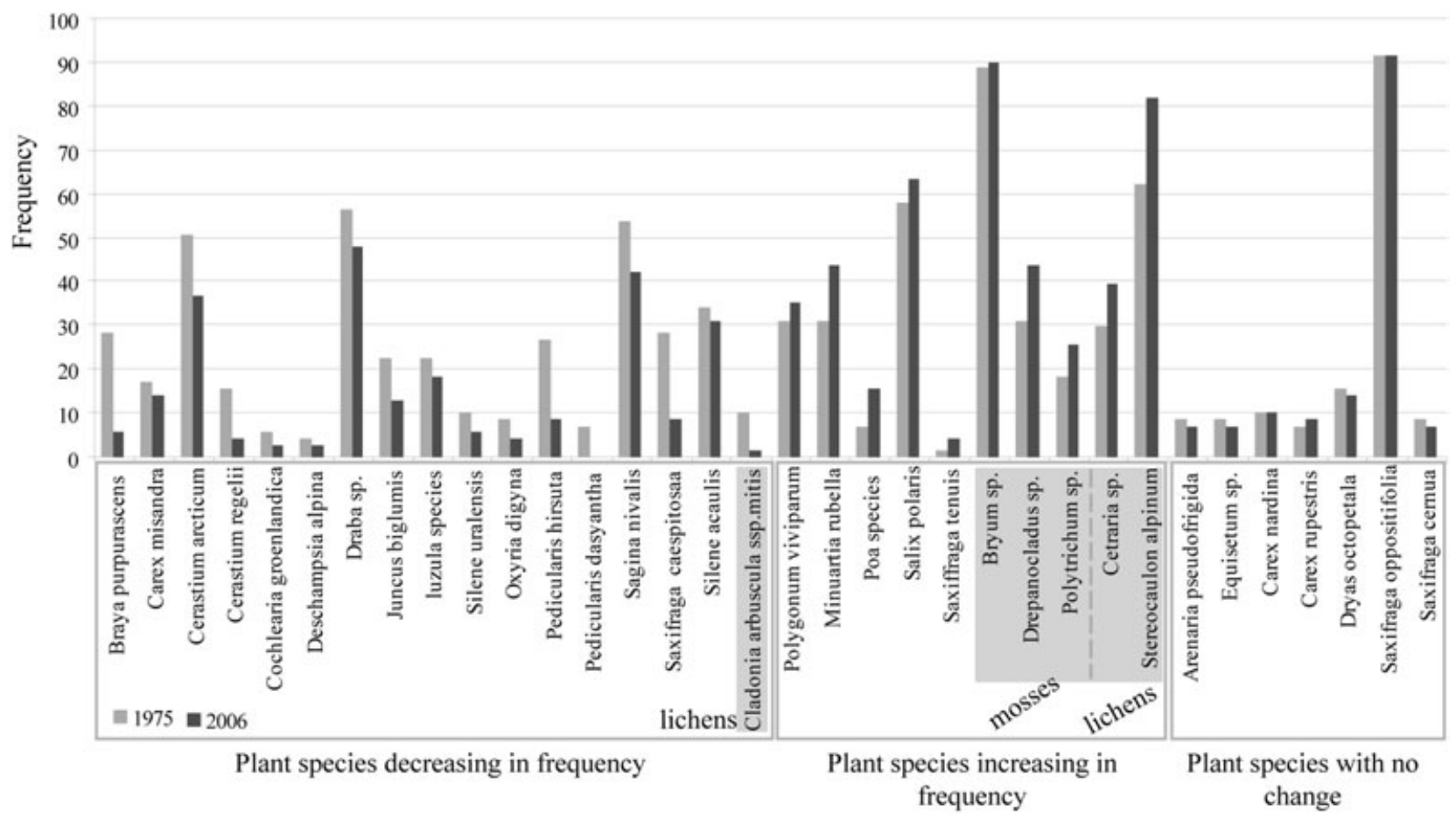

Fig. 2 Frequency of species occurrences at all 85 sampling sites in 1975 and 2006.

interval. Hence, the survey data took into account the complete species list established for this sector by Brossard et al. (1984). In addition to the vegetation cover, we also noted the presence of any biotic crust. This takes the form of a black or grey pellicle, which is a combination of cyanobacteria, cyanophytes, cyanophylous lichens (Ochrolechia frigida, Lecanora epibryon and Lecophysma finmarkicum), and some small liverworts belonging to the Cephalozia and Cephaloziella genera (Nilsen et al. 1999). By grouping certain taxa in this manner, information is lost, but observations are made fully comparable both in space (from one sampling site to another) and in time (from one date to another). This constraint takes precedence in the context of a study designed to provide a spatial assessment of the vegetation succession. Figure 2 lists the vegetation characteristics that were processed for a comparative analysis between the years 1975 and 2006.

The data collected were arranged in two tables, with the rows corresponding to the georeferenced sampling sites, and the columns corresponding to the vegetation items observed and selected. The information was analysed in several steps. First, a tally was made of the characteristics (species or others) that had appeared or disappeared. This yielded an initial indication of the general pattern of change in the study area. The data were then analysed quantitatively using STATISTICA 7. By coupling the correspondence analysis and ascending hierarchical classification (Benezecri 1992; Le Roux \& Rouanet 2004), all of the elements (vegetation items, and sampling sites for 1975 and 2006) were positioned in a factorial space. This plot was used firstly as a system of reference for defining the trajectories, corresponding to vectors, followed by the sampling sites over time, and then to see how these trajectories corresponded to transitions between the various vegetation types, defined by ascending hierarchical classification. The geographical location of the sampling sites meant that the results could be mapped in such a way as to show whether the movements observed in the factorial space corresponded to the spatial logic of vegetation dynamics across the different environmental contexts. Before analysing the results, some practical questions about how the method was implemented require clarification.

The data were collated in a binary table, and were coded as either present ( 1 ) or absent (0). For species that were present at more than $50 \%$ of the sampling sites, a column was added in which their absence was coded as (1) and their presence was coded as (0). This was because the absence of a species that is found at a majority of locations is a discriminating feature worth highlighting. In this way, the absence of Salix polaris, Saxifraga oppositifolia, Sterocaulon alpinum and mosses was noted. By contrast, some species were excluded from processing when they were inventoried only once or twice, as was 


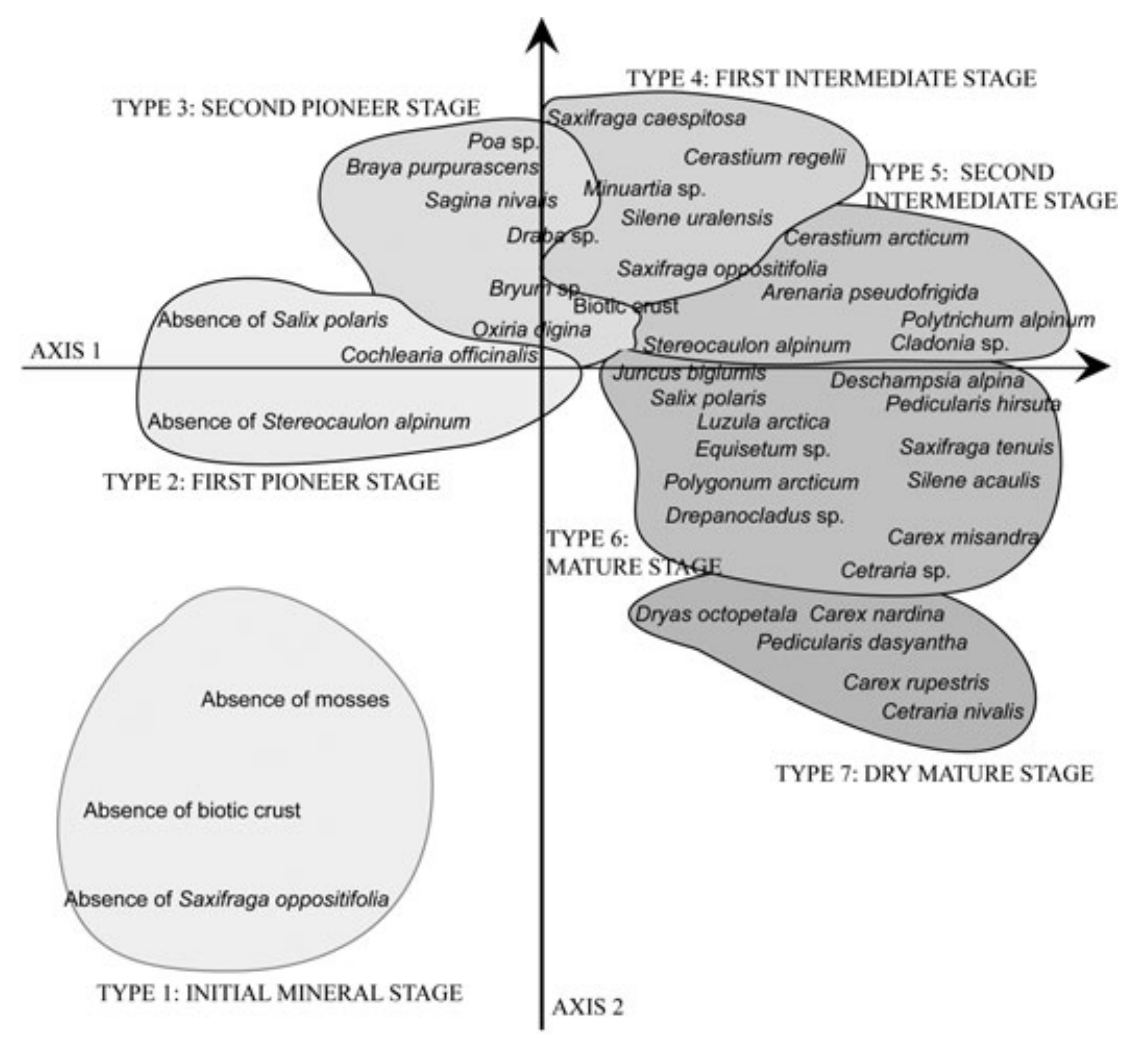

Fig. 3 Correspondence analysis: species locations in factorial space and groupings resulting from the classification. the case with Saxifraga aizoïdes, Cassiope tetragona, Papaver dahlianum and Saxifraga nivalis.

The method used is based on correspondence analysis, which makes it possible to process tables of binary data, and to define the resulting space structured by the axes. Another useful feature of this method is that the spaces for variables (vegetation species) and for individuals (sampling sites) are merged into the same ordination space. This property is known as distributional equivalence (Escofier 1978). The relative positions of individuals and variables are therefore helpful in giving a thematic meaning to the different factorial axes, as it is easier to make a connection between the logical structure arising from the analysis (relative position of the species in the factorial space) and the geographical structure of the space (relative position of the sampling sites on the map). Three axes of the correspondence analysis were sufficient to explain more than $48 \%$ of the inertia: this is a high percentage, as binary coding, which generates a large number of empty cells in the data matrix, leads to a drop in the levels of inertia. It must be noted here that the factorial space was calculated first using the 1975 data alone. The sampling sites for 2006 were then projected into this space by the "supplementary elements" technique that is possible in correspondence analysis (Greenacre 1984). As a result of successional change (i.e., the appearance or disappearance of species), each sampling site occupies a different factorial-space position in 2006 compared with 1975, which can be expressed graphically by a vector. This application made it possible to show successional trends, and to identify explanatory factors related to the environment. We coupled factor analysis with a method of ascending hierarchical classification (AHC, using Ward's metric): seven vegetation types were defined. In the final step, vegetation types for the two dates were mapped against a background made up of vertical aerial photographs. Each vegetation type was identified by a separate colour. This made it possible to see which sampling sites had changed type, and where they were located. The results furnished by the map were then interpreted to show the successional trends (or stabilities) observed.

\section{Results}

\section{General assessment}

Figure 3 shows the frequency of occurrence of the taxa (species or type) from all of the sampling sites on the two dates. No new species appeared. Pedicularis dasyantha no longer occurred in 2006. Taxa can be classified into three 
groups depending on whether their frequency of occurrence increased, decreased or remained the same.

Vegetation maturation. Certain vascular species that are recognized as pioneers became less frequent. This is true of Braya purpurascens, the frequency of which fell from 28 to 5\%, and of Cerastium arcticum and of Saxifraga cespitosa. By contrast, species that are ubiquitous or are characteristic of mature vegetation groups either maintained (Dryas octopetala, Carex nardina and Carex rupestris) or increased their frequency (Salix polaris and Polygonum viviparum). The increased occurrence of bryophytes, such as Drepanocladus sp. and Polytrichum sp., from 30 to $40 \%$ and from 18 to $25 \%$, respectively, can be explained on the same grounds, as these species are associated with mature tundra formations. Lichens of the genus Cetraria increased in frequency from 30 to $40 \%$, and Sterocaulon alpinum increased in frequency from 60 to $80 \%$.

It is noteworthy that although Cetraria sp. occur at a larger number of sampling sites, the cover of these lichens has fallen drastically on mature tundra, because of the overgrazing by reindeer that were reintroduced in 1978 (Elvebakk 1997). Cetraria sp. exhibit increased dispersion but decreased biomass. Despite the uncertainties about the qualitative change in cover since 1975, the losses observed in the stable tundra environment are too sizeable and too widespread to be dismissed as differences in observational calibration between the two dates. However, apart from the effect on Cetraria sp., our investigation detects no other impact of reindeer on vegetation. Indeed species that are particularly prone to grazing, such as Dryas octopetala, Silene acaulis (Wada 1999), Saxifraga oppositifolia and Salix polaris (Rønning 1996), do not appear to have been affected, at least in terms of their frequency.

The increased frequency and the cover of Stereocaulon alpinum in stabilized moraine and sandur habitats are very significant: this species is an indicator of a transition from pioneer to mature stages, with a ratio of mineral/ vegetation cover that tends to be balanced.

The drying of the environment. A decrease in the frequency of species that are characteristic of wet habitats (Rønning 1996), such as Cerastium regelii (from 15 to 4\%), Juncus biglumis (from 22 to 12\%), Cochlearia officinalis and Deschampsia alpina, was observed over the interval. Although they favour less water-logged habitats, Luzula sp. and Silene uralensis also declined in frequency. Conversely, the vascular species peculiar to dry settings, such as Polygonum viviparum and Minuartia rubella (Rønning 1996; Aiken et al. 1999) increased in frequency. This observation may be related to the depth of the seasonal thaw and soil drainage. Soils are well drained overall, as silt- and clay-sized particles make up only a small fraction of the substratum almost everywhere in the study area. The soils have a tendency to dry out earlier in the growing season, which is a constraint for most species. Many of the instances of decline in taxa frequency can be interpreted as a consequence of drying.

\section{Changes from pioneer to mature vegetation types}

To make it readable, only the plant species names and the ellipsoids grouping sampling sites of the same type are included in Fig. 2. Even though they have not been explicitly indicated here, the distributional equivalence does allow the individual positions of the sampling sites to be inferred. As the environmental conditions characterizing each sampling site (water flow, age and edaphic conditions) are known from different sources (additional field observations, literature and maps), it is possible, when interpreting the graph, to determine how they are related to vegetation types, and to their changes. The vegetation types are ranked from 1 to 7 along a parabolic crescent. This geometric shape reveals a logical structure that also organizes the plant species distribution. This characteristic shape is a sign that the data obey an ordered relationship, sometimes referred to as the Gutman effect (Escoffier 1979). Such a structure indicates that the interpretations of axes 1 and 2 cannot be distinguished, and that they obey the same logic. In our case, this structure can be interpreted as a temporal gradient extending from the initial mineral stages to mature stages, via the pioneer and intermediary stages that punctuate the colonization process. Axis 3, which is not shown on the graph, defines a secondary wet-dry gradient. It distinguishes species that favour wet habitats, such as Equisetum sp., Deschampsia sp., Juncus biglumis and Cochlearia officinalis, from species that prefer dry habitats, such as Cetraria nivalis, Carex nardina, Carex rupestris and Pedicularis dasyantha.

\section{Community types associated with stages in vegetation development}

On the basis of distributional equivalence, each plant species is positioned at the barycentre of the different sampling sites at which it is observed. In this way, certain taxa are seen to be poorly dispersed, and strongly characterize a given type. For example, Cetraria nivalis, Carex nardina, Carex rupestris and Pedicularis dasyantha are observed exclusively, or almost exclusively, at type-7 (dry mature) sampling sites; Saxifraga tenuis, Deschampsia sp. and Equisetum sp. are characteristic of type-6 (mature) sampling sites. Other taxa, such as Dryas octopetala, Luzula 
sp. and Poa sp., are slightly more dispersed across the types, but they remain within a limited sector of the factorial space. On the other hand, certain ubiquitous taxa, situated in the middle of the graph, are dispersed over a large number of types, and are thus not very discriminating: Bryum sp., Saxifraga oppositifolia, biotic crust and, to a lesser extent, Stereocaulon alpinum fall into this category. By analysing the correlations between taxa and sampling site types in this way, it is possible to specify the content and the significance of the different vegetation types recognized. Because the ordered relationship, brought out by correspondence analysis, is defined as a temporal gradient, we have used the term "stage" here to define the vegetation types. Moreover, as we also have certain reference points from old aerial photographs (Fig. 1), or from radiocarbon dating (Corbel 1966), the different stages can also be ascribed to particular age brackets (Moreau 2005).

Vegetation type 1: initial mineral stage. This refers to the initial stage of colonization, when the sampling sites, marked exclusively by characters of absence, are devoid of vegetation, and are located on recently defrosted fringes or active transit areas subject to fluvioglacial dynamics. Less often, vegetation type 1 is found in stable areas, where succession has been impeded by particularly limiting factors, such as a coarse-grained substratum or by late snowmelt in some moraine depressions. Judging from our sampling sites, the response time for the advent of the first species is 5-10 years.

Vegetation type 2: first pioneer stage (10-30 years). The landscape remains very mineral, and characters of absence are still dominant at the sampling sites. However, several pioneer taxa are observed initiating the colonization process, such as mosses (Bryum sp.), biotic crust, Braya purpurascens, Sagina nivalis and Saxifraga oppositifolia. Cochlearia officinalis and Juncus biglumis may occur where a fine-grained substratum and humidity are combined. None of the species observed at this stage are exclusive to it: they all occur in the following stage too.

Vegetation type 3: second pioneer stage (30-100 years). Eleven new species were counted, including Saxifraga cespitosa, Draba sp., Cerastium arcticum, Cerastium regelii, Poa sp., Minuartia rubella, Oxyria digyna and Salix polaris. This group, which is more variable from one sampling site to another, occupies the bulk of the areas liberated since the end of the Little Ice Age: moraine belts and stabilizing sandur strata. Plant cover values remain modest, at less than $10 \%$.
Vegetation type 4: first intermediate stage (100150 years). At this stage the number of plant species stabilizes, although Stereocaulon alpinum appears for the first time in this stage, and is immediately very frequent. Braya purpurascens is still present, although it is rarer, thereby displaying its pioneer credentials. Silene uralensis is also observed. This phase of stabilization is expressed by cover values of $20-30 \%$, and, at a large majority of sampling sites, by the presence of mosses, biotic crust, Saxifraga oppositifolia, Cerastium arcticum, Draba sp., Sagina nivalis and Salix polaris. This type occupies the spaces that were established at around the maximum of the Little Ice Age: i.e., terminal moraine ridges and defunct proglacial outwash cones (Mercier 1998). Secondly, Cochlearia officinalis, Poa sp., Juncus biglumis and Cerastium regelii occur at sampling sites in the wetter settings of intramoraine depressions, or in sedimentation areas on sandurs.

Vegetation type 5: second intermediate stage. This stage characterizes the long transition leading to mature tundra vegetation. Distinctive species appear, such as Pedicularis hirsuta, Polygonum viviparum, Cetraria sp., Polytricum alpinum, Luzula sp. and Drepanocladus sp., and Sterocaulon alpinum is typically abundant. Plant cover attains 50\%, giving the landscape its dominant physionomy. The time bracket in which these environments evolved is unknown, because precise temporal indicators are lacking. These sectors are older than the Little Ice Age, but are younger than the raised glaciomarine terraces, three samples of which were radiocarbon dated, and yielded inclusive dates of between 9260 and 9650 B.P. (Corbel 1966). These local measurements are consistent with the results of other work carried out in this part of Spitsbergen (Salvigsen 1977; Forman \& Miller 1984).

Vegetation type 6: mature stage (mesic and wet). Vegetation types 6 and 7 dominate the glaciomarine terraces: these may be raised marine landforms or old, long-stabilized sandurs. We have no indicators to date the time boundary between the intermediate and mature stages. Vegetation type 6 includes the species that are typical of the mature tundra already observed in vegetation type 5 , but they tend to be found at all of the sampling sites, which display greater floristic richness. The fruticose lichens Cetraria delisei and Cetraria islandica, the abundant large thalli of which gave this tundra its characteristic appearance in 1975, have been largely eradicated by the recent reintroduction of reindeer. This vegetation group has a preference for well-sorted sediments (sands and granules), and has brought about a degree of edaphic development (brown soils). A wet subtype, which the classification did not distinguish, is 
marked by the presence of Equisetum sp., Juncus biglumis and Deschampsia alpina. Where the soil is waterlogged and its grain-size distribution is heterogeneous, metric-sized stone rings form.

Vegetation type 7: mature dry stage. Vegetation type 7 is distinguished from type 6 by its environmental conditions, rather than by any age criterion. The limestone bedrock outcrops from place to place on the marine terraces, and is subjected to frost action, thereby producing a gelifraction layer, where patterns such as stripes and small stone rings develop. The vegetation cover rate drops and the number of species is reduced: Dryas octopetala, Carex misandra, Carex nardina, Carex rupestris, Pedicularis dasyantha and Cetraria nivalis are characteristic of this group. This type has two subtypes, corresponding to the microhabitats that our sampling procedure did not differentiate between. Sites facing south-west that are sheltered from the wind are characterized by Cassiope tetragona, Lycopodium selago, Tomentypnum nitens and Ptilidium ciliare. Exposed sites situated along the limestone bars, and used as look-out posts by certain predatory birds, are distinguished by the presence of Xanthoria elegans, Hypnum revolutum, Rhacomitrium lanuginosum and Alectoria ochroleuca.

\section{Vegetation change between 1975 and 2006}

Figure 4 shows how the relative percentage of each of the seven vegetation types changed in the 31-year interval. Paradoxically, the initial mineral stage (vegetation type 1) occurred at a slightly increased number of sampling sites, because although some sampling sites evolved beyond this type by integrating new species, others regressed and returned to this initial stage as a result of hydrolic erosion removing the vegetation. The number of sampling sites with pioneer vegetation types 2 and 3 declined as the cover there matured into intermediate vegetation types 4 and 5, which became more common. The number of sampling sites with mature vegetation types 6 and 7 remained largely stable, even though the slightly higher number of locations of the dry mature type tends to confirm the drying effect that we observed in the assessment by species.

Changes between vegetation types. In 1975 and $2006,56 \%$ of the sampling sites were unchanged under our coding system, with these being mostly the mature stages. By projecting the sampling sites for 2006 in the factorial space, the changes observed can be expressed by vectors. The original position of these vectors is marked by black dots in Fig. 5. Figure 5a shows only intertype movements, so as to avoid overcrowding the graph. Intratype movements are shown in Fig. 5b. Type changes were recorded for 31 of the 85 sampling sites. Most changes were between neighbouring vegetation types, and were part of a general pattern of maturation. The number of regressions was logically higher for the pioneer stages, and lower for the more mature stages. However, progressions were very common in the median section of the graph, with a particularly strong transition between vegetation types 3 (second pioneer stage) and 4 (first intermediary stage). Some sampling sites that were at the mineral stage in 1975 had matured to the second pioneer stage by 2006, which conforms to the timescale established elsewhere (Moreau 2005) to calibrate the process of vegetation colonization. Certain major regressive phenomena were marked by a return from the mature stages to the mineral stage: here, we found the effect of vegetation destruction by proglacial waters eroding the older levels of the tundra. As the glacial front recedes, the successive moraine ridges dam the different water streams, which are diverted and flow into a few main courses. The cones through which all of the water is discharged from the moraines are then undersized, and tend to spread outwards, encroaching on older stable levels: the sampling sites that markedly regressed were victims of this

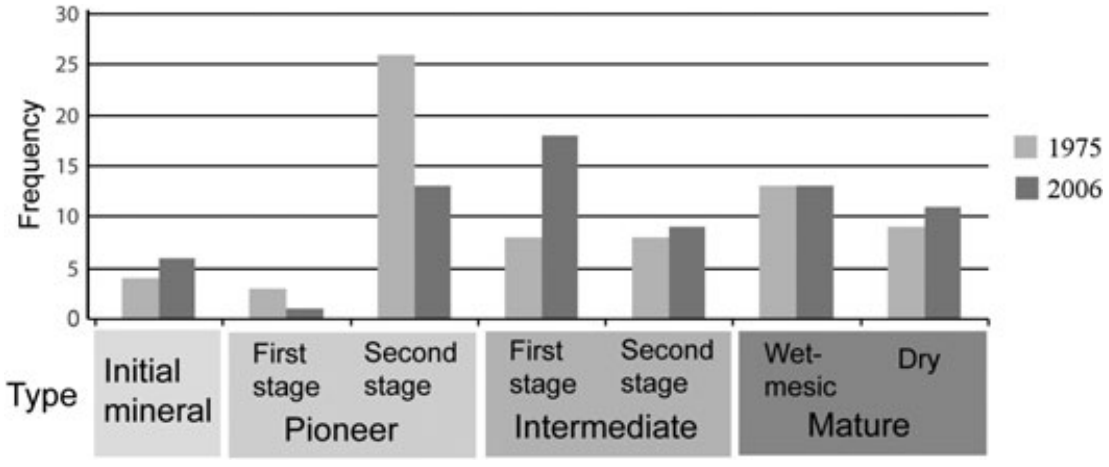

Fig. 4 Number of sampling sites corresponding to each vegetation type in 1975 and 2006 


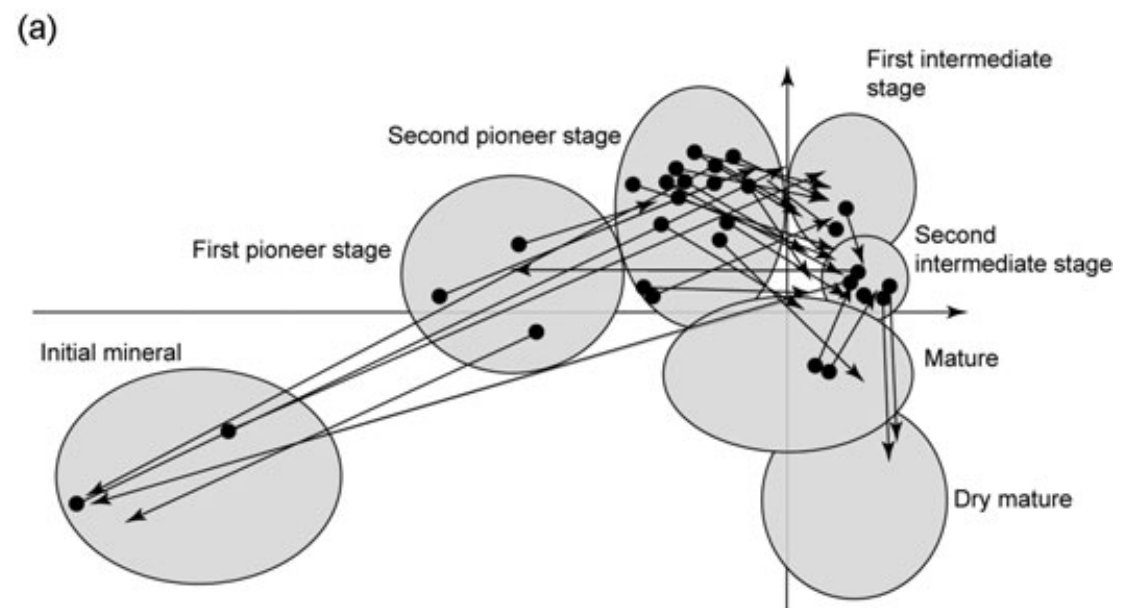

(b)

Fig. 5 (a) Changes between vegetation types. The graph corresponds to the correspondence analysis with the sampling sites that changed vegetation type between 1975 and 2006. (b) Changes within vegetation types. The graph corresponds to the correspondence analysis with the sampling sites that did not change vegetation type between 1975 and 2006. In both plots, the black dots show the positions of the sampling sites in factorial space in 1975, and the lines show the paths of change from 1975 to 2006.

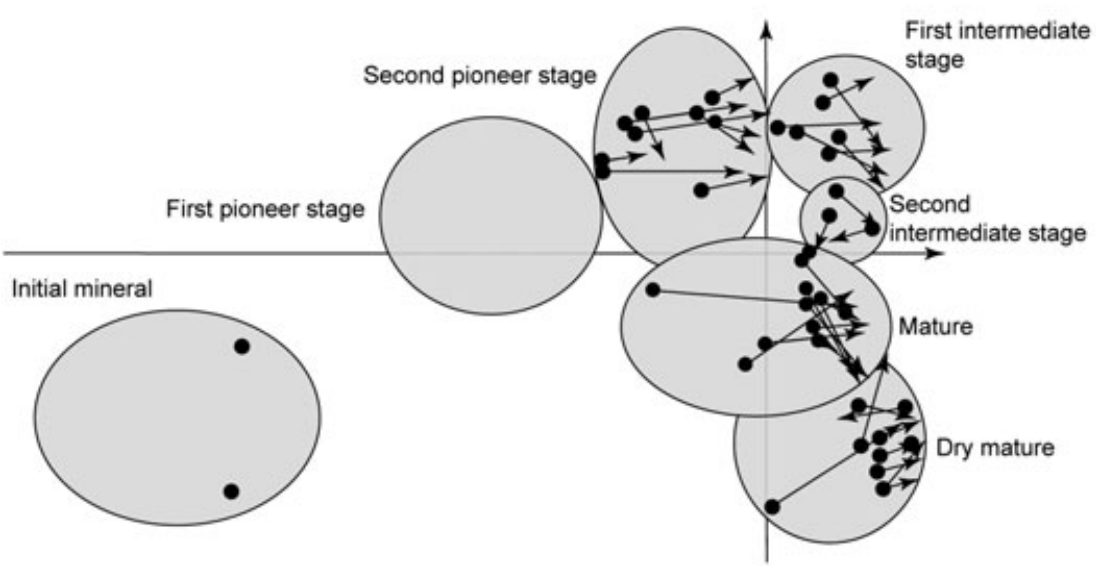

scenario. Two other more sustained regressive shifts were observed between vegetation types 6 and 5, resulting from a decrease in the number of species observed at the corresponding sampling sites. In all likelihood this is further evidence of drying, because the species that vanished are associated with wet environments.

Changes within vegetation types. These changes are concentrated on the right-hand section of Fig. 5b, and affect vegetation types $3-7$, indicating that readjustments exist in most settings. Here again, the direction of the vectors conforms to the ordered relationship: regressive movements are rare, and analysis of the corresponding sampling sites shows that they are linked to the inexplicable erratic disappearance of a species.

Mapping the vegetation succession. A spatial visualization (Fig. 6) was produced by creating a mosaic of aerial photographs: two symbols have been added for each plot, the ones on the left apply to 1975 and the ones on the right to apply to 2006. The colours refer to the seven vegetation types identified by the classification. In addition to the successions observed, a logical distribution of vegetation types appeared. In 1975, the mineral stages were found at the glacier fronts, or on active sandurs that were flooded each year. To a large extent, the pioneer stages occupied the core of the moraine amphitheatres and the sandurs undergoing stabilization. The intermediate stages, which were less frequent, were concentrated on the terminal moraine arcs or the stabilized sandurs. Vegetation type 6 occupied the older sections of the sandurs and the marine accumulation terraces, whereas vegetation type 7 was strung along the linear limestone outcrop, easily seen on the photograph, crossing the area from the north-west to the south-east. Comparison between 1975 and 2006 data shows that few sampling sites with vegetation of types 6 and 7 underwent change. However, the drying phenomenon was in evidence: the disappearance of hydrophilous species from vegetation type 6 brought about a regression to type 5, whereas the appearance of xerophilous species in vegetation type 6 


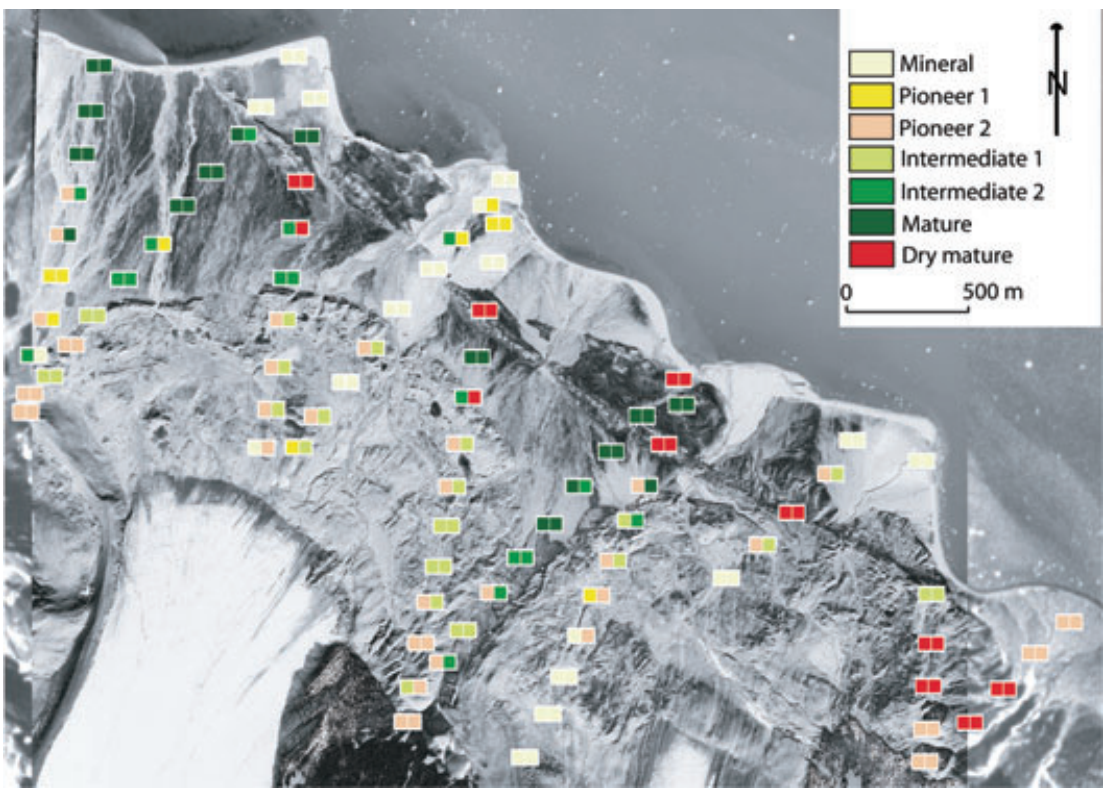

Fig. 6 Map of vegetation succession stages for 1975 (squares on the left) and 2006 (squares on the right). marked a transition towards type 7 . The large number of sampling sites that remained at the mineral stage is another stable feature in the overall pattern. This observation is mainly explained by proglacial activity preventing colonization from getting underway. The variation in water level in the lagoon in the north-west is another explanatory factor. As for the rest, it appears that the most intensive succession was concentrated in the moraines, with a marked progression from vegetation type 3 to type 4 . Succession of the same type was also observed on the external sandurs, but was caused by much more localized phenomena when certain channels were no longer functional. Instances of regression are also observed in this context, as channels that have dried up and are undergoing colonization may be flooded when there is a rise in the water level, or during a spring thaw. The advanced phases of maturation from vegetation type 4 to type 5 and beyond are less frequently observed. It can be surmised that when the process of vegetation colonization reaches these phases of development, it occurs on a longer timescale than our 31-year observation interval was able to capture.

\section{Discussion}

Regular sampling along transects is a commonly employed method for investigating spatial variations of plant species and vegetation types. Repeating this type of protocol after a 31-year interval meant making adjustments to ensure the two series of observations were comparable. The precautions taken at the time of the initial survey-ground marking, and the precise photog- raphy of the sampling sites and their settings-made it easier to identify the sampling sites and accurately reposition the sampling quadrant. The sampling site locations have now been recorded in a GPS system for future work.

A further consideration was the level of precision of the information collected. This had to remain consistent in space, from one sampling site to another, and in time, from one survey date to another. Accordingly, some species that were too rare were either omitted or were grouped with others. The vegetation types we have identified do not correspond to plant communities in the phytosociological sense of the term, but to biogeographical entities that we use as markers to calibrate changes in vegetation. Moreover, by coupling correspondence analysis with ascending hierarchical classification, we have been able to measure these changes using vectors (factorial distance), and to represent them in two ways: first, by plotting them on a graph to reveal their logical structure, which is essentially time-related; and second, by mapping them to reveal their spatial pattern. However, the scope of some observations is limited because species abundance evaluations are subjective and had to be omitted. For instance, the quantitative impact of overgrazing by reindeer could not be measured, because the presence/absence criterion fails to provide an accurate measure of the substantial decline in the cover of species such as Cetraria delisei or Cetraria islandica. On the scale of the study zone as a whole, the species that were missing from the second survey were mostly species characteristic of wet habitats. This was interpreted as a sign that soils have dried out because the permafrost level has fallen, although this is merely a hypothesis. A measurement of 


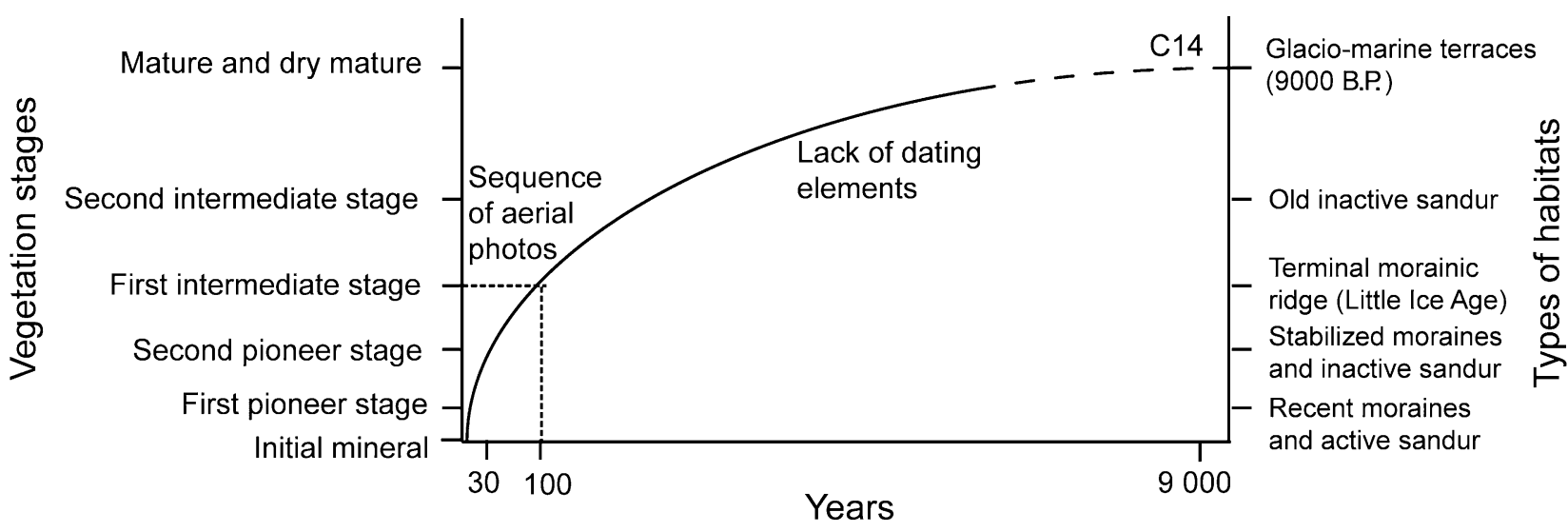

Fig. 7 Diagram of the different stages of vegetation succession on glacial forelands in Svalbard. The line shows the trajectory of vegetation over time relative to the various vegetation stages and habitat types.

species abundance would have enabled a better diagnosis of the phenomenon. The observation protocol needs to be improved to overcome this difficulty. The solution envisaged consists of measuring abundance from frequencies. To this end, the same $1-\mathrm{m}^{2}$ quadrat divided into $10 \times 10 \mathrm{~cm}$ squares can be used. Species are recorded in terms of their presence or absence in each square. The number of squares where a species is observed gives its abundance. This mode of observation is more reliable because it does away with the subjective character of the evaluation, but it is more time-consuming. This constraint can be limited by observing just 16 squares taken at random from the 100 squares of the quadrat. Tests have shown that abundance differences between the exhaustive method and the sampling method are insignificant (Moreau 2005). This, then, is a potential solution for ensuring that abundance measurements remain comparable over long intervals.

Despite these limitations, the method used was precise enough to reveal the major changes that have affected the vegetation in the study area as a whole. The essential contribution was to show how, over a given interval of time, the sampling sites have shifted within a typological reference space. Many studies of vegetation dynamics concentrate on stabilized areas where dating features can be found, say from photographs in which the successive stages of glacial retreat can be identified. In this way, the spatial position provides a sort of time reference. Hodkinson et al. (2003), who also worked on the Midre Lovénbreen glacier, opted to study unreworked moraine zones only. Plant colonization is considered, then, as a straightforward ordered process that passes through a series of progressive stages (Kuc 1964; Ziaja \& Dubiel 1996; Nakatsubo et al. 1998; Kume et al. 2003). The direct survey reported here supplements that approach. The succession of stages of colonization shown on the factorial graphs (Fig. 5) relates to a timescale that can be calibrated from Fig. 7. The first three stages of the succession can be completed in less than 100 years. The time vectors clearly show the continuity of the process that leads from the mineral stage to the mature stages, but they also show that transitions from one type to the next did not occur everywhere with the same intensity. Over the 31-year interval, all sampling sites recorded changes, and adjustments are underway everywhere, even in the mature tundra. Analysis of these changes reveals that they are not all consistent with the temporal logic underpinning plant colonization, marked by the succession of the various stages. The impact of certain processes that interfere with vegetation dynamics can be appraised. The major role played by run-off can be noted, as 13 sampling sites were reworked: this erosional process contributes to maintaining large areas at the mineral stage, both in the zone within the moraine amphitheatre and in the outlying sandurs. Run-off also accounts for most of the regressive phenomena observed: these regressions may be partial, where run-off is occasional and slight, or complete, with a return to the initial stage where water flow is intense; even sections of mature tundra were affected in the observation interval. Other processes have far less effect than run-off. In some instances, plant colonization is impeded by the grain-size characteristics of the substratum (natural paving), or by site exposition (such as a hollow where snow is trapped and only melts late in the growing season). Solifluxion is also a factor of constraint observed at 11 sampling sites, although its effect is most marked on the axial part of the lobes, whereas the edges remain stable: colonization was able to continue at the sampling sites affected by solifluxion, as seven of them changed type, with six shifting from type 3 to type 4 , and with one shifting from type 4 to type 5. 
A final issue is the representative character of the work carried out. Most of the studies cited here relate to zones that have recently been opened to colonization (moraines and recent sandurs) because of glacial melting, and so omit the transition stages leading to mature tundra. The characteristics of our study site, where ancient glaciomarine terraces occur alongside more recent sandur areas, pre-dating the Little Ice Age, provide insight into how these biogeographical units with their very different timescales, and which are widespread in polar regions, are related to one another by vegetation dynamics. The time interval under study is long enough to give some idea of this process.

\section{Conclusion}

The method is an important aspect of this paper. Our study specifies, for an applied case, how changes in vegetation can be observed at relatively long intervals by comparing repeated samplings from sites that are regularly spaced along transects. Although localization problems have been quite satisfactorily resolved, more difficulty was found in deciding what informational content could be exploited while ensuring the two data series remained comparable. We opted to sacrifice precision for the sake of consistency. In this way, we could be sure the changes observed were real, and were not mere artefacts generated by the protocol. The downside is that we detected major changes only. The discussion section suggests how this limitation might be overcome, and how observations might be made more precisely, especially by measuring species abundance from frequency calculations.

As the data collected were referenced in space and time, a processing procedure was required to cover both of these aspects. Correspondence analysis coupled with classification revealed the time pathways of the sampling sites, whereas the mapping of types at the two dates brought out the spatial pattern of vegetation dynamics. Correlating the graphs and maps provided an interesting basis for interpreting the results.

The results are consistent with many earlier studies. Time is the main factor differentiating vegetation types from the mineral and pioneer stages through to mature types, where moisture and aridity appear to be the distinguishing features. The changes affecting vegetation were measured against these reference types. Most of the trajectories followed by the sampling sites are consistent with this general pattern, and reveal the continuity of the pattern as the vectors follow on from one vegetation type to the next. The vector length provides a ready measure of change, and is an indicator of the dynamics of the sampling sites. Change and continuity are found in all types of settings, although with different characteristics. Vectors for the recent moraine and sandur sectors show that plant colonization may be rapid, as some sampling sites have completed several stages in the succession within the 31-year interval. Conversely, vectors for the mature tundra sectors are shorter, and indicate only slight adjustments in sampling site composition, the meaning of which is less obvious; however, the hypothesis that the soils have dried out is advanced, as wet-habitat species have been lost from several sampling sites. The impact of run-off in explaining regression has been shown, as has the effect of certain limiting factors such as grain size or the late melting of snow cover.

\section{Acknowledgements}

The fieldwork for this study was carried out with logistical resources provided by the Jean Corbel research base, operated by the French Polar Institute. We are grateful to the anonymous reviewers for their advice on the paper.

\section{References}

Aiken S.G., Dallwitz M.J., Consaul L.L., McJannet C.L., Gillespie L.J., Boles R.L., Argus G.W., Gillett J.M., Scott P.J., Elven R., LeBlanc M.C., Brysting A.K. \& Solstad H. 1999. Flora of the Canadian Arctic Archipelago. Accessed on the internet at http://www.mun.ca/biology/delta/arcticf on 3 April 2009.

Benzecri J.-P. 1992. Correspondence analysis handbook. New York: Dekker.

Brossard T. 1977. Les équilibres biogéographiques liés aux équilibres dynamiques de versants dans les paysages du Svalbard (Ny-Ålesund). (Relation between biogeography and slope dynamics in Svalbard landscapes [Ny-Ålesund].) PhD thesis, Ecole Pratique des Hautes Etudes en Sciences Sociales, Paris.

Brossard T. 1985. Évolution biogéographique d'un secteur de moraine au Svalbard (glacier Loven central) bilan quantitatif 1978-1981. (Biogeographical evolution of a sector of moraine in Svalbard [central Lovén glacier]: quantitative assessment 1978-1981.) Inter-Nord 17, 33-46.

Brossard T., Déruelle S., Nimis P.L. \& Petit P. 1984. An interdisciplinary approach to vegetation mapping in High Arctic Environments, Ny-Ålesund, Svalbard. Phytocoenolgia $12,433-453$.

Corbel J. 1966. Datation au carbone 14 des terrasses marines de la Baie du Roi. (Radiocarbon dating of marine terraces in the Kongsfjorden area.) In: Spitsberg 1964 et premières observations 1965. (Spitsbergen 1964 and first observations 1965.) Pp. 309-314. Lyon: Audin Éditions.

Elvebakk A. 1997. Tundra diversity and ecological characteristics of Svalbard. In F.E. Wielgolaski (ed.): Ecosystems of the world. Vol. 3. Polar and alpine tundra. Pp. 347-359. Amsterdam: Elsevier. 
Escofier B. 1978. Analyse factorielle et distances répondant au principe d'équivalence distributionnelle. (Factor analysis and distances in accordance with the distributional equivalence principle.) Revue de Statistique Appliquée 26, 29-37.

Escofier B. 1979. Une représentation des variables dans l'analyse des correspondances multiples. (A way of representing variables in multiple correspondence analysis.) Revue de Statistique Appliquée 27, 37-47.

Forman S.L. 1990. Post-glacial relative sea-level history of northwestern Spitsbergen, Svalbard. Geological Society of America Bulletin 102, 1580-1590.

Forman S.L. \& Miller G.H. 1984. Time-dependent soil morphologies and pedogenetic processes on raised beaches, Brøggerhalvhøya, Spitsbergen, Svalbard Archipelago. Arctic and Alpine Research 16, 381-394.

Greenacre M.J. 1984. Theory and applications of correspondence analysis. London: Academic Press.

Hagen J.O., Liestøl O., Roland E. \& Jørgensen T. 1993. Glacier atlas of Svalbard and Jan Mayen. Norsk Polarinstitutt Meddelelser 129. Oslo: Norwegian Polar Institute.

Hodkinson I.D., Coulson S.J. \& Webb N.R. 2003. Community along proglacial chronosequences in the High Arctic: vegetation and soil development in north-west Svalbard. Journal of Ecology 91, 651-663.

Klanderud K. \& Birks H.J.B. 2003. Recent increases in species richness and shifts in altitudinal distributions of Norwegian mountain plants. The Holocene 13, $1-6$.

Kuc M. 1964. Deglaciation of Treskelen-Treskelodden in Hornsund, Vestspitsbergen, as shown by vegetation. Studia Geologica Polonica 11, 197-206.

Kume A., Bekku Y.S., Hamba Y.T. \& Kanda H., 2003. Carbon isotope discrimination in diverging growth forms of Saxifraga oppositifolia in different successional stages in a High Arctic glacier foreland. Arctic, Antarctic, and Alpine Research 35, 377-383.

Lefauconnier B. 1990. Fluctuations récentes des glaciers dans le Kongsfjord, $79^{\circ} \mathrm{N}$ Spitsberg. (Recent fluctuations of glacier fronts in Kongsfjorden, $79^{\circ} \mathrm{N}$ Spitsbergen.) Inter-Nord 19, 449-453.

Le Roux B. \& Rouanet H. 2004. Geometric data analysis: from correspondence analysis to structured data. Dordrecht: Kluwer Academic Publishers.
Mercier D. 1998. Le ruissellement au Spitsberg. L'impact d'un processus azonal sur les paysages d'un milieu polaire, presqu'île de Brøgger. (Runoff in Svalbard. The polar world facing climate changes.) PhD thesis, Université Blaise Pascal Clermont-Ferrand II.

Minami Y., Okitsu S. \& Kanda H. 1997. Relationship between plant community and topographic factors on the moraine at deglaciated Arctic terrain in Ny-Ålesund, Svalbard. Bulletin of the Faculty of Agriculture Tamagawa University 37, 21-30.

Moreau M. 2005. Dynamique des paysages végétaux depuis la fin du Petit Âge Glaciaire au Spitsberg. Analyse intégrée de la reconquête végétale des marges proglaciaires. (Dynamics of vegetated landscapes since the end of the Little Ice Age: analysis of plant colonization in proglacial areas.) PhD thesis, Université Blaise Pascal Clermont-Ferrand II.

Moreau M., Laffly D., Joly D. \& Brossard T. 2005. Analysis of plant colonization on an Arctic moraine since the end of the Little Ice Age using remotely sensed data and a Bayesian approach. Remote Sensing of Environment 99, 244-253.

Nakatsubo T., Bekku Y., Kume A. \& Koizumi H. 1998. Respiration of the belowground parts of vascular plants: its contribution to total soil respiration on a successional glacier foreland in Ny-Ålesund, Svalbard. Polar Research 17, 53-59.

Nilsen L., Elvebakk A., Brossard T. \& Joly D. 1999. Mapping and analysing Arctic vegetation: evaluating a method coupling numerical classification of vegetation data with SPOT satellite data in a probability model. International Journal of Remote Sensing 20, 2947-2977.

Rønning O.I. 1996. The flora of Svalbard. Oslo: Norwegian Polar Institute.

Salvigsen O. 1977. Radiocarbon dating and the extension of the Weichselian ice sheet in Svalbard. Norsk Polarinstitutt Arbok 1976, 209-224.

Wada N. 1999. Factors affecting the seed-setting success of Dryas octopetala in front of Brøggerbreen (Brøgger Glacier) in the High Arctic, Ny-Ålesund, Svalbard. Polar Research 18, 261-268.

Ziaja W. \& Dubiel E. 1996. Vascular plant succession during contemporary deglaciation in the mountains of Nordenskiöld Land, Spitsbergen. In W.E. Kawczyk (ed.): XXIII Sympozjum Polarne. (23rd Polar Symposium.) Pp. 99-104. Sosnowiec: University of Silesia. 